\title{
The interface between organizational learning capability, entrepreneurial orientation, and SME growth
}

Article

Accepted Version

Altinay, L., Madanoglu, M., De Vita, G., Arasli, H. and Ekinci, Y. (2016) The interface between organizational learning capability, entrepreneurial orientation, and SME growth. Journal of Small Business Management, 54 (3). pp. 871-891. ISSN 1540-627X doi: https://doi.org/10.1111/jsbm.12219 Available at https://centaur.reading.ac.uk/47957/

It is advisable to refer to the publisher's version if you intend to cite from the work. See Guidance on citing.

Published version at: http://dx.doi.org/10.1111/jsbm. 12219

To link to this article DOI: http://dx.doi.org/10.1111/jsbm.12219

Publisher: Wiley

All outputs in CentAUR are protected by Intellectual Property Rights law, including copyright law. Copyright and IPR is retained by the creators or other copyright holders. Terms and conditions for use of this material are defined in the End User Agreement.

www.reading.ac.uk/centaur 
Central Archive at the University of Reading

Reading's research outputs online 


\title{
The Interface between Organizational Learning Capability, Entrepreneurial Orientation, and SME Growth
}

\author{
by Levent Altinay, Melih Madanoglu, Glauco De Vita, Huseyin Arasli, and
} Yuksel Ekinci

This paper investigates the interface between organizational learning capability, entrepreneurial orientation (EO), and small business performance. It reports on the findings from 350 small and medium enterprises (SMEs) in North Cyprus operating in the services and retailing sectors. The findings indicate a positive relationship between EO and sales and market share growth, but not between EO and employment growth. There is also a positive relationship between organizational learning capability and EO. This paper contributes to the small business management literature by providing a bolistic analysis of the interface between organizational learning capability, EO, and growth.

\section{Introduction}

The contemporary dynamism of the business environment has been forcing businesses to remain competitive by exploring new opportunities (Hitt et al. 2001). Strategic orientation has been defined as the principles that direct and influence the activities of businesses and that inform the behaviors aimed at exploiting opportunities so as to gain and sustain competitive advantage (Hakala 2011). A strategic orientation, therefore, steers the direction of businesses and assists them in the process of identifying customer needs and wants proactively by introducing new products and services ahead of competitors. This pattern, in turn, influences the industry at large through the establishment of new standards (Escriba-Esteve, Sanchez-Peinado, and Sanchez-Peinado 2008).

The strategic orientation of businesses has attracted widespread attention from entrepreneurship scholars. According to the entrepreneurship literature, businesses create value and growth through engaging in entrepreneurial activities (Spicer and Sadler-Smith 2006). Such activities include the identification and exploitation of business opportunities through innovation, proactive behaviors, and risk-taking decisions (Covin and Slevin 1989, 1991; Spicer and Sadler-Smith 2006). However, such an entrepreneurial approach can only offer temporary competitive advantages. Businesses also have to think creatively about how to sustain

Levent Altinay is Professor of Strategy and Entrepreneurship and Research Area Leader at Faculty of Business, Oxford Brookes University, Oxford, United Kingdom.

Melih Madanoglu is Associate Professor at College of Business, Florida Atlantic University, Boca Raton, Florida.

Glauco De Vita is Professor of International Business Economics at Centre for Business in Society (CBiS), Coventry University, Coventry, United Kingdom.

Huseyin Arasli is Professor of Management, Eastern Mediterranean University Faculty of Tourism, Famagusta, TRNC, Mersin 10 Turkey.

Yuksel Ekinci is Professor of Marketing and Reputation, Henley Business School, Reading University, Reading, United Kingdom.

Address correspondence to: Levent Altinay, Oxford Brookes University, Gipsy Lane Campus, Headington, Oxford, OX3 0BP, UK. Tel: +44 (0)1865 483832; Fax: (0)1865 483878; E-mail: laltinay@brookes.ac.uk. 
competitive advantages by adopting a long-term orientation and taking strategic actions including strategic planning and the acquisition and analysis of information to improve decisionmaking (Cohen and Sproull 1996; Morgan and Strong 2003). Therefore, entrepreneurial and strategic management perspectives need to be combined in order to be able to develop the strategic orientation needed to achieve and sustain competitive advantages (Escriba-Esteve, Sanchez-Peinado, and Sanchez-Peinado 2008; Hakala 2011).

Entrepreneurial orientation (EO) is one of the most popular constructs explaining value creation activities and business growth. It encompasses firm-level behaviors, in particular, entrepreneurial processes, practices, and decision-making activities (Lumpkin and Dess 1996). EO reflects the propensity of small and medium enterprises (SMEs) to engage in the "pursuit of new market opportunities and the renewal of existing areas of operation" (Hult and Ketchen 2001, p. 901). In spite of its importance in explaining how firms develop and exploit business opportunities through engaging in entrepreneurial activities, extant research on EO has been criticized for neglecting organizational learning capability and knowledge creation, thereby falling short of explaining the processes through which growth is achieved (Covin and Lumpkin 2011). This clearly suggests the adoption of a combined approach to explaining performance, reiterating the point made earlier that, besides the implementation of entrepreneurial processes and practices, businesses need to develop internal systems and procedures to enhance knowledge building capacity and enable organizational learning (Cohen and Sproull 1996; Floyd and Wooldridge 1999). In particular, entrepreneurial activities could be sustained through developing learning capability processes and knowledge creation, leading to continuous and proactive entrepreneurial engagement and sustainable growth (Floyd and Wooldridge 1999). Organizational learning capability (hereafter OLC) can be defined as the ability of an organization to create, transfer, and integrate knowledge and modify its behavior with a view to improving its performance (Jerez-Gomez, Cespedes-Lorente, and ValleCabrera 2005). It encompasses organizational and managerial factors including managerial commitment, openness, a sense of belonging to the organization, experimentation, knowledge transfer, and integration, all of which facilitate the learning process (Goh and Richards 1997).
The relationship between OLC, EO, and performance has been studied individually (Covin and Lumpkin 2011; Grinstein 2008). However, very few studies have adopted a strategic management perspective to understanding the combined and simultaneous effects of strategic orientations on growth in a small business context. The notable exception is the excellent contribution by Alegre and Chiva (2013) who using structural equation modeling on a data set from Italian and Spanish ceramic tile producers, find that OLC (alongside innovation) significantly influence the EO-performance relationship.

More importantly, although the analysis of learning has become an increasingly significant study area in recent years, there is a dearth of studies investigating the role of organizational learning in the survival and growth of small businesses (Hakala and Kohtamaki 2011; Wales, Gupta, and Mousa 2013; Wang 2008). In particular, OLC has been identified as a missing link in the examination of the relationship between EO and growth (Jerez-Gomez, Cespedes-Lorente, and Valle-Cabrera 2005; Zhao et al. 2011). This paper aims to fill this glaring gap by investigating the interface between OLC, EO, and small business growth. By doing so, our study offers new insights into how SMEs exploit their learning capabilities to stimulate EO and thus improve performance. In particular, the paper contributes to the small business management literature by demonstrating that OLC of small firms facilitates EO, which in turn, influences sales and market share growth positively.

The study also investigates the mediating role of EO between OLC and performance, a research avenue that has not been explored before. Investigation of this issue is particularly important because although the empirical evidence supporting this argument is still limited, it is through entrepreneurial ventures that a firm maximizes the impact of OLC on firm performance (Ar and Baki 2011; Hakala and Kohtamaki 2011). In this respect, a further contribution of the study to the small business management literature lies in providing empirical evidence that EO broadens the scope of small firms for learning and thus maximizes the impact of OLC on small firm's sales and market share growth.

The paper draws upon data collected from 350 SMEs in North Cyprus where firms constantly confront a complex and turbulent external environment caused by political and economic instability on the island. North Cyprus is not an internationally recognized State. It is 
known as a de facto State, segregated and isolated from the southern Republic of Cyprus and heavily dependent upon Turkey, the sole country to recognize North Cyprus, both politically and economically (Howells and KrivokapicSkoko 2010). The economy of North Cyprus has the characteristics of a typical island economy with limited resources and imports exceeding exports. There is no heavy industry such as manufacturing, and the economy is dependent upon the services sector, primarily tourism, and higher education, and continuing economic aid from Turkey (Katircioglu 2010; Mehmet 2010). Due to economic and political embargoes on North Cyprus, the country cannot export its agricultural and textile products. Significantly, the continuing economic sanctions have made it impossible for aid agencies or international companies to operate in the region (Howells and Krivokapic-Skoko 2010).

Despite international economic and political sanctions, North Cyprus has developed a dynamic economy. More than 95 percent of small and medium sized firms are private sector organizations contributing to the public sector dominated economy (Mehmet 2010; Tanova 2003). There is a strong public sector involvement in the economy, with the public sector being the largest customer of SMEs, offering tax reductions and exemptions as well as providing incentives and subsidies to stimulate the start-up and growth of SMEs (Tanova 2003). A recent survey noted that small businesses operating in the "protective environment" in North Cyprus are economically productive despite the economic sanctions (Howells and KrivokapicSkoko 2010). Such an environment is believed to be fertile for new information and knowledge, characteristics which align to those seen as core features of entrepreneurial firms. Indeed, as pointed out by Wang (2008) and Zhao et al. (2011), the more entrepreneurial a firm is, the more it engages in information and knowledge acquisition in order to respond to growth opportunities.

\section{Theoretical Review}

Previous research investigating the interface between strategic behavior and firm performance has focused on large firms in large economies leaving a glaring research gap in strategic behavior-performance relationship in SMEs in small and dependent economies (Parnell 2013). In particular, understanding the strategic orienta- tions of SMEs is crucial as the strategic orientation adopted by SMEs determines the extent of SMEs run demand and competitor analysis, and the way they acquire and exploit knowledge about market opportunities and engage in productmarket innovations leading to growth (AragonSanchez and Sanchez-Marin 2005; EscribaEsteve, Sanchez-Peinado, and Sanchez-Peinado 2009). It is now well documented in the literature that relying solely on an entrepreneurial mind-set provides an incomplete understanding of SMEs' performance (Wiklund and Shepherd 2005). EO can create temporary competitive advantages that cannot be sustained long term (Ireland, Hitt, and Sirmon 2003). Understanding the reasons for differentials among SMEs' sustainable competitive advantage therefore requires analyzing their learning and knowledge creation capability and how this can lead to continuous and proactive entrepreneurial engagements and sustainable growth (Floyd and Wooldridge 1999; JerezGomez, Cespedes-Lorente, and Valle-Cabrera 2005). In fact, Baker and Sinkula (2009) state that EO is a learning construct. SMEs that learn more effectively than their competitors improve faster and more effectively than their competitors and achieve superior new product and service development. Effective analysis and integration of market knowledge facilitates innovation, risk taking and proactiveness leading to product and service success, increased market share, profitability, and sustainable competitive advantage (Baker and Sinkula 2009). Likewise, SMEs adopting a strong EO engage in proactive and extensive environmental scanning, serving as a stimulus for information acquisition and exploitation and opening up scope for learning about market opportunities and growth (Wang 2008). Based on this reasoning, we take a more holistic view of investigating SME growth through analyzing the combined effects of EO and OLC on performance.

This paper aims to evaluate the relationship between different orientation constructs, namely OLC, EO, and SME growth holistically. It is international in scope, collecting and articulating information about the market conditions of a developing country characterized by an uncertain environment, both politically and economically. The conceptual framework (Figures 1 and 2) and research hypotheses are based on theories of EO, learning capability, and firm growth. Model development is based on the approach of Baker and Sinkula (2009). The framework consists of two competing models 


\section{Figure 1}

\section{Conceptual Model 1}

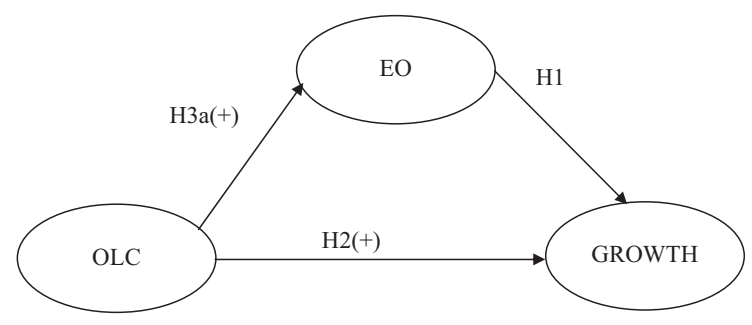

OLC, organizational learning capability; EO, entrepreneurial orientation, GROWTH, SME growth.

where OLC is first an exogenous construct (Model 1) and then employed as a mediator (Model 2).

EO has emerged as a multidimensional firmlevel construct within the strategic management and entrepreneurship literatures over the years. Originally proposed by Miller (1983) and later modified by Covin and Slevin (1991), EO describes certain firm-level outcomes and management-related preferences and beliefs with regard to an organization's overall business operations, its response to customers' needs and product offerings and interactions with competitors (Covin, Green, and Slevin 2006). It consists of four main factors, namely innovativeness, proactiveness, risk taking, and autonomy (Lumpkin and Dess 1996). Innovativeness is connected with seeking creative solutions to problems and needs (Covin and Slevin 1989). It involves promoting and supporting novel ideas, and experimentation and creative processes that may lead to new products. Proactiveness involves shaping the environment by introducing new products, technologies, and administrative techniques rather than merely reacting to market change (Lumpkin and Dess 1996). Risk taking involves the willingness to commit significant resources to opportunities which have a reasonable chance of costly failure (Lumpkin and Dess 1996; Miller and Friesen 1983). Autonomy refers to the organization's willingness to delegate responsibility to individuals or a team to take independent action in bringing forth an idea or a vision and carrying it through to completion (Lumpkin and Dess 1996). As a strategic choice, these dimensions of EO are embedded in an organization's philosophy, which drives decision-making and behavior toward creating new goods, pursuing new methods of production or of offering services, and entering into new markets (Stevenson and Jarillo 1990). EO, therefore, could be an important indicator of the way in which an organization is structured and its ability to outperform competitors. As such, EO is paramount for improving a firm's competitive advantage and performance. It contributes to organizational transformation and strategic

\section{Figure 2}

\section{Conceptual Model 2}

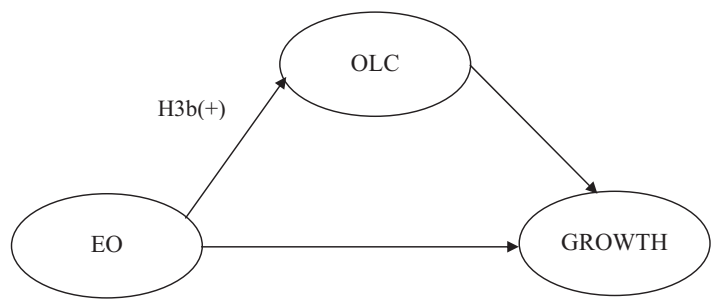

OLC, organizational learning capability; EO, entrepreneurial orientation; GROWTH, SME growth. 
renewal through the creation and combination of organizational resources and competences (Wales, Gupta, and Mousa 2013; Zahra, Kuratko, and Jennings 1999). An entrepreneurially oriented firm engages in product innovation, undertakes risky ventures, and possesses proactiveness (Lumpkin and Dess 1996; Miller 1983). By searching for product/service-market prospects, entrepreneurial firms tend to concentrate on customer needs and competitors' offerings, thereby becoming more market oriented (Miles and Arnold 1991; Morris and Paul 1987).

The analysis of learning has become an increasingly important aspect of entrepreneurship research (Hakala 2011; Wang 2008). More recently, learning has been considered from a strategic perspective, as a strategic resource and a key contributor to the competitive advantage of small firms (Covin and Lumpkin 2011; Zhao et al. 2011). Both learning orientation, conceptualized as a firm's values which influence its propensity to create and use knowledge (Sinkula, Baker and Noordewier 1997), and OLC, conceptualized as enablers of creation, acquisition, transfer, and integration of knowledge (Jerez-Gomez, Cespedes-Lorente, and ValleCabrera 2005), influence a firm's capability to engage in entrepreneurial activities. Learning orientation reflects values and norms represented in a firm's behaviors and processes whereas OLC is seen as the ability of a firm to create an enabling platform to generate, transfer, and integrate knowledge and modify its behavior with a view to improving its performance (DiBella, Nevis, and Gould 1996).

Despite the general consensus around these uncontroversial notions, it needs to be acknowledged that there are still different views regarding the nature of learning at the organization level. Some theorists view the organization as a collection of individuals (human perspective), while others view it as the systems, structures, and procedures of the organization (nonhuman perspective). These two different perspectives mark different viewpoints in addressing the link between learning and organizational performance, with some scholars focusing on the capabilities of individual members (e.g., Guzzo, Jette, and Katzell 1985), others in terms of teams (e.g., Edmondson 2002), and others still on the capacity of the organization as a whole to acquire, disseminate, utilize, and embed new knowledge (e.g., DiBella, Nevis, and Gould 1996). Recently, Jerez-Gomez, CespedesLorente, and Valle-Cabrera (2005) developed a four-dimensional OLC framework which underlines how the learning process stems from the knowledge acquisition of the individuals and then progresses with the exchange and integration of this knowledge until a corpus of collective, organizational knowledge is created, including knowledge on mechanisms (routines, systems, etc.) by which the exchange of knowledge can be better fostered and embedded. In so doing, the framework transcends the critical issue about the level at which learning can take place and the connections between the individual, teams, and the organization. Drawing on this perspective, our intent is to present a holistic perspective of OLC as it relates to the phenomenon of EO. The view of OLC presented here, therefore, can be distinguished from other perspectives that have focused on specific elements of organizational learning as exemplified by Cohen and Sproull's (1996) collection of articles on the wide range of approaches employed in relevant literature.

Jerez-Gomez, Cespedes-Lorente, and ValleCabrera's (2005) OLC framework hinges on the principle that the effective development of OLC requires four dimensions, namely, managerial commitment, systems perspective, openness and experimentation, and knowledge transfer and integration. Managerial commitment involves the support of leadership for organizational learning. People in managerial positions should acknowledge the importance of learning and actively promote the acquisition, creation, and transfer of knowledge (Nonaka and Takeuchi 1995). Management should place learning at the heart of strategy formulation and implementation (Hult and Ferrell 1997; Ulrich, Jick, and Glinow 1993). Likewise, managers should convey and communicate the importance of learning to the employees (Senge 1990; Slater and Narver 1995). Finally, management should play an instrumental role in initiating and managing change through encouraging learning among the employees (Nonaka 1994; Nonaka and Takeuchi 1995). A systems perspective entails creating a sense of identity and belonging to an organization (Senge 1990; Sinkula 1994). The organization should be considered as a system of shared mental models through which information is acquired, disseminated, and shared (Miller 1996; Senge 1990). This implies that organizational learning goes beyond individual learning and acquires a collective nature (JerezGomez, Cespedes-Lorente, and Valle-Cabrera 2005). Therefore, the presence of a common 
language is seen as a crucial facilitator of knowledge sharing and integration (Grant 1996). Openness involves welcoming the arrival of new ideas both from internal and external environments allowing the generation and acquisition of new knowledge (Leonard-Barton 1992; Sinkula 1994). Openness to new ideas and perspectives also favors experimentation, an essential aspect of generative learning (Jerez-Gomez, Cespedes-Lorente, and Valle-Cabrera 2005). Experimentation entails coming up with innovative solutions to current and future problems (Garvin 1993; Leonard-Barton 1992) and it requires a culture stimulating creativity and learning through making mistakes (Naman and Slevin 1993; Slater and Narver 1995). Knowledge transfer and integration refer to internal transfer and integration of knowledge (JerezGomez, Cespedes-Lorente, and Valle-Cabrera 2005). These two interrelated processes should facilitate the transfer of knowledge among individuals without any internal barriers (Kofman and Senge 1993; Nicolini and Menzar 1995). This requires transparent and abundant communication through various platforms including personnel meetings, forums, and workshops (Nonaka 1994; Slater and Narver 1995). The knowledge transfer and integration taking place through these processes is, in turn, expected to lead to "collective ownership learning" and "organizational memory" (Chiva, Alegre, and Lapiedra 2007).

The multidimensional nature of the OLC framework described above appears to us to be particularly suited in application to SMEs. Of course much work has already been conducted on learning in SMEs (see, inter alia, Cope 2005; Deakins and Freel 1998; Gibb 1997). This body of literature has highlighted that small firms are not scaled-down versions of larger firms (upon which most of the research has focused) as smaller firms face different challenges (due to scale, resources, expertise, etc.) which may well impact EO (for instance, the four main factors of EO identified by Lumpkin and Dess 1996). Such work has also brought to the fore how SME entrepreneurs learn by doing, learn from trialand-error, from peers, and from customers. However, much of this research has focused on the entrepreneur as a unit of analysis rather than intrafirm level OLC, which constitutes our focus.

The measurement of the performance and growth of small businesses is a complex area, with different approaches proposed in the litera- ture. Dobbs and Hamilton (2007) identified six approaches adopted by previous research to studying small firm growth, namely: stochastic, descriptive, evolutionary, resource-based, learning, and deterministic approaches. The stochastic approach to growth argues that there are numerous factors that affect growth and/or decline. While recognizing this, those studies following a descriptive approach are concerned with how a small firm adapts internally in order to grow. The evolutionary perspective to growth advocates that small firm growth is contingent upon the interaction between internal and external factors. The resource-based view postulates that growth is primarily the result of idiosyncratic configurations and management of resources. The learning approach emphasizes the importance of knowledge acquisition and learning by the employees and firm, positing that learning created by the individuals and the firm facilitates business growth. The deterministic approach to small firm growth argues that variations in growth can be explained by different variables related to people, the firm, and the business environment. Studies exploiting these approaches contribute to our understanding of small business growth through explaining growth promoted by managerial strategies (employee recruitment and development, product and market development, internationalization and collaboration), characteristics of the entrepreneur, environmental/industry specific factors and characteristics of the firm (Reijonen et al. 2012). Though the research on the influence of firm and the firm's resources on growth is fairly robust, little research has been done on the influence of strategic orientations on SME growth. In particular, the combined effects of EO and OLC have been neglected by previous small business management research.

In the empirical literature, a variety of measures have been utilized to evaluate small business growth: sales volume (Basu and Goswami 1999; Fischer and Reuber 2002; Rue and Ibrahim 1998); profit levels (Birley and Westhead 1990); number of employees (Birley and Westhead 1990); and number of customers and increases in market share (Baldwin et al. 1994). However, there are practical limitations with respect to gathering reliable data about these measures as small business owners are often unwilling to provide and share this information. Barkham et al. (1996) emphasize that the least problematic growth measurement is sales turnover, which is always 
recorded and can act as a reliable indicator of size and growth. This study, therefore, utilizes sales growth as one of the indicators for growth. This is average annual sales growth from the business start-up to the present (Basu and Goswami 1999). However, in their research into ethnic minority entrepreneurship, Fadahunsi, Smallbone, and Supri (2000) state that Pakistani and Indian Sikh respondents declined to answer questions about their sales turnover because of tax reasons. Taking this into consideration, it is thought that utilizing sales turnover alone as an indicator of business growth may be insufficient for extracting growth-related information. Ireland, Reutzel, and Webb (2005) emphasize that although there is little evidence of the impact of $\mathrm{EO}$ on job creation, job creation has been an important target of government support for small business growth. In view of this, Ireland, Reutzel, and Webb (2005) call for further research examining the role of firms' entrepreneurship on job creation. Given that the firms comprising our sample include gift shops and cafes, it is more likely that increased market share or sales might be more desirable or indeed achievable than an increase in the number of employees (given the size of the working population in what is a constrained economy). However, for the sake of comprehensiveness we also use employment growth as one of our performance measures. As underlined in previous studies (Altinay and Altinay 2006; Barkham et al. 1996; Naman and Slevin 1993), measuring growth of SMEs is a challenging, complex, and difficult issue, with practical limitations with respect to gathering reliable data as small business owners are often reluctant to provide and share financial information. This study therefore relies on more than one measure to quantify the performance of firms. The measurement of growth consists of sales growth, market share growth, and employment growth.

\section{Hypotheses Development}

\section{The Effects of EO on SME Growth}

EO is crucial in improving an SME's competitive advantage and performance. Empirical studies have largely found that firms with a more EO perform better (Baker and Sinkula 1999; Wales, Gupta, and Mousa 2013; Wiklund 1999). EO contributes to organizational transformation and strategic renewal through creation and combination of organizational resources and competences (Zahra, Nielsen, and Bogner 1999). An entrepreneurially oriented firm actively innovates through new products and services, acts proactively in order to identify changing consumer needs, responds to competitors moves, undertakes risky ventures, and delegates responsibility to their employees for effective decision-making (Lumpkin and Dess 1996). Entrepreneurship scholars have also attempted to explain the performance of SMEs by investigating their EOs. $\mathrm{EO}$ is a firm-level construct that encourages certain SME-level outcomes and management-related preferences with regard to an organization's overall business operations, product offerings, interactions with competitors, risk taking, and management structure (Covin, Green, and Slevin 2006; Lumpkin and Dess 1996). As a strategic choice, it is an embedded organizational philosophy that drives decision-making and behavior toward creating new goods, new methods of production and new geographical and/or product markets (Stevenson and Jarillo 1990).

Recent years have raised interest toward a better understanding of the relationship between EO and growth. High growth has been linked to a firm's entrepreneurial behavior including innovativeness, proactiveness, and risk taking behavior (Casillas, Moreno, and Barbero 2010; Covin, Green, and Slevin 2006; Dess and Lumpkin 2005; Madsen 2007; Wang and Altinay 2012). In their study of family, small and medium sized companies in Spain, Casillas, Moreno, and Barbero (2010) found a positive relationship between EO and growth, in particular, the positive influence of innovativeness and proactiveness on profitability. Confirming the positive relationship between EO and growth, Covin, Green, and Slevin (2006) found that the relationship between EO and sales growth was positive among manufacturing firms that employ autocratic decision-making and exhibit an emergent strategy formation process. Similarly, Dess and Lumpkin (2005) state that firms grow through new venture opportunities and strategic renewal. Madsen (2007) who undertook a longitudinal analysis to understanding the growth of Norwegian SMEs also found that there is a positive relationship between $\mathrm{EO}$ and employment growth. They contributed to the literature by identifying that resources that may be inimitable also have some influence on performance compared to competitors. Perks (2006) also found a positive relationship between EO and growth of SMEs in France and Germany and 
explained it with reference to the characteristics of these firms, in particular their management styles. Given these arguments, we have set our hypothesis as:

\section{H1: EO has a positive effect on SME growth (sales} growth, market share growth, and employment growth).

\section{The Effects of OLC on SME Growth}

There is no consensus in the literature about the link between OLC and business performance (Popper and Liphitz 2000; Prieto and Revilla 2006). The divergence of views is due to the fact that cause-and-effect relationships are not necessarily straightforward and can hardly be defined clearly (Yeo 2003). One of the reasons is that the effects of OLC on performance may occur step-by-step and creating the mechanisms to develop the capacity to learn may be complex. Another reason is that many factors affect organizational outcomes including the organization's environment, leadership, and organizational culture (Prieto and Revilla 2006). In spite of conflicting perspectives, there is clear evidence that OLC may improve business performance. Senge (1990) argues that, over a long period, superior performance depends on OLC. Other scholars also recognize the importance of OLC as crucial to overall performance (Nahapiet and Ghoshal 1998; Soo, Devinney and Midgley, 2004). Recent empirical studies also give support to the impact of OLC and different forms of knowledge on performance (Palacios-Marques, Ribeiro-Soriano and Gil-Pechuan 2011; Prieto and Revilla 2006; Theriou and Chatzoglou 2009). Organizations with a greater capacity to learn are able to identify changing consumer needs and wants more easily than their competitors, leading to better organizational performance (Bontis, Crossan, and Hulland 2002; Prieto and Revilla 2006; Tippins and Sohi 2003). Consequently we propose the following hypothesis:

H2: There is a positive relationship between OLC and SME growth (sales growth, market share growth, and employment growth).

\section{The Effects of OLC and EO}

There is convincing evidence for both the view (Bell, Whitwell, and Lukas 2002) that learning may have a two-way interaction with $\mathrm{EO}$, and the view (Hakala and Kohtamaki 2011) that learning capability enables companies to successfully combine different orientations to generate performance enhancing behaviors. Most previous research agrees that OLC influences EO positively. Floyd and Wooldridge (1999) propose that knowledge creation in corporate entrepreneurship contributes to the renewal of OLC leading to novel entrepreneurial ideas and behaviors. Weerawardena (2003) and Weerawardena and O'Cass (2004) state that a market-focused learning capability leads to higher degrees of entrepreneurship, as market driven firms are superior in market sensing and customer-orientated capabilities. Confirming these claims, Garcia-Morales, Llorens-Montes, and Verdu-Jover (2007) find that the most innovative and entrepreneurial firms have effective learning mechanisms. Similarly, investment in employee training, education, and skill development is a precursor of entrepreneurial activities (de Jong and Vermuelen 2006). Siguaw, Simpson, and Enz (2006) advocate that an organization should have a strong learning philosophy in order to be entrepreneurial.

It is also well documented that EO contributes to the learning capability of a firm (Sinkula, 1994). Entrepreneurial firms operate in complex, uncertain, and turbulent environments that tend to push firms toward knowledge acquisition and exploitation (Wang 2008). Such firms are more proactive and, by and large, extensively engage in environmental scanning activities involving information acquisition and dissemination (Huber 1991). They are innovative and risk tolerant, constantly exploring and experimenting new business ideas through creating mechanisms for knowledge acquisition and exploitation (Slater and Narver 1995). Using data from 213 medium-to-large U.K. firms, Wang (2008) found that EO positively influences learning and broadens scope for learning through stimulating firms to challenge the status $q u o$ and introduce flexibility and change in their way of doing things. Given all this, we formulate our hypotheses as:

H3a: OLC influences EO positively. H3b: EO influences OLC positively.

\section{The Mediating Effects of EO and OLC on SME Growth}

Starting with Floyd and Wooldridge (1999), there is a stream of research that claims that OLC has a positive relationship with EO. There is also evidence in the literature suggesting that 
OLC has a positive impact on EO, which in turn, has a positive impact on firm performance. These studies generally view EO as an exogenous construct which influences organizational performance through knowledge creation (Li, Huang, and Tsai 2009) and market information (Keh, Nguyen, and Ng 2007). Reporting on the results of a survey, McAdam, Armstrong, and Kelly (1998) concluded that continuous learning and improvement leads to increased entrepreneurial activities and ultimately to better organizational performance. In a study of IT companies, Koc (2007) emphasized that organizational learning creates a strong innovation capacity and performance through acquisition, integration, and exploitation of new knowledge. In their studies of SMEs in Turkish Science and Technology parks, Ar and Baki (2011) also found that OLC has a positive impact on process innovation and ultimately on performance. Thus, learning mechanisms established internally enable firms to question the status quo on a regular basis and push for continuous improvement, leading to a more flexible and adaptable way of doing things. Such an approach increases both the productivity and efficiency of firms. Aragon-Correa, Garciamorales, and Cordonpozo's (2007) survey results also showed that firms' ability to engage in entrepreneurial activities and innovate successfully is influenced by their OLC. The learning capability of firms enables them to experiment with new ideas and deliver superior new services and products leading to business growth. On this basis, we have set our hypothesis as:

H4a: The OLC-performance relationship is mediated by EO; OLC has a positive impact on EO, which, in turn, has a positive impact on SME growth (sales growth, market share growth, and employment growth).

Although the literature supporting this view is limited, it is also argued that EO has a positive impact on OLC which, in turn, has a positive impact on firm performance (Wang 2008). Covin, Green, and Slevin (2006) state that OLC is a crucial dimension of firms' strategic activities. How firms choose to develop their learning mechanisms, use different sources for learning and inform and refine their strategic decisions and activities influences the effect of EO on performance. Recognizing this, in her study of 213 medium-to-large U.K. firms, Wang (2008) investigated the EO-performance rela- tionship by incorporating learning as a mediator. It became apparent that OLC mediates the EO-performance relationship. EO leads to the stimulation of new ideas and transformation of routine business practices, creating a responsive organizational environment to market opportunities. Wang (2008, p. 649) therefore concluded that $\mathrm{EO}$ has a positive impact on learning orientation which, in turn is conducive to firm performance. In line with this, Slater and Narver (1995) also argued that OLC underpins firms' self-renewal ability and creates a platform that drives continuous improvement in entrepreneurial activities and performance. We therefore set our hypothesis as:

\section{H4b: The EO-performance relationship is medi- ated by OLC; EO has a positive impact on OLC which, in turn, has a positive impact on SME growth (sales growth, market share growth, and employment growth).}

\section{Method \\ Setting and Sample}

The research hypotheses were tested using data collected from SME owners in Northern Cyprus services and retail organizations including hotels, restaurants, rent-a-car, gift shops, retail shops, cafes, and travel agencies. Retail and tourism are the two primary industries represented in this study. SMEs in this sample have between 2 and 50 employees. We selected 500 SMEs from the Business Directories of Trade and Commerce Associations and other published business directories in the country with the aim of achieving a minimum of 250 responses in order to test our model via the Structural Equation Modeling approach (Jöreskog and Sörbom 1996).

The first step in conducting the survey was distributing the questionnaires to the owners and explaining to them the aim of our study. A total number of 400 questionnaires were personally distributed to the owners of the small and medium sized touristic organizations by our research team. The participants were kindly requested to fill out the questionnaires in a selfadministered manner. The managers were also given an assurance about confidentiality. Approximately 40 questionnaires were not returned although the owners were reminded several times via telephone and e-mail. About 10 questionnaires were biased and thus excluded from 
the data evaluation process. By the cutoff date for data collection, a total number of 350 questionnaires were personally retrieved, yielding a response rate of 87.5 percent. More than half of responding companies (57 percent) were family firms. The mean of number of employees was 10.7. As mentioned before, a large majority of sample firms (83 percent) had fewer than 10 employees. The oldest firm in our sample was 40 years old while the mean organizational age for the sample was 10 years.

This study thus collected self-reported data from single informants, which introduces the potential for common method variance bias. First, to alleviate concerns about common method bias, we ensured the anonymity of the respondents to reduce evaluation apprehension. Next, we conducted the Harman's one-factor test (Podsakoff and Organ 1986) to rule out any possibility for common method variance. We entered all variables into an exploratory factor analysis (EFA) which showed that more than one factor emerged from this analysis. In addition, no factor accounted for the majority of variance in these variables. The highest variance was 28.9 percent. As a result, we concluded that the variance in this study can be attributed to the constructs of interest rather than to the measurement method.

\section{Measures}

As the knowledge accumulation around the construct of EO has been substantial and studies mainly used the measure initially developed by Miller (1983) and later modified by Covin and Slevin (1989). The present study also adopts this widely used measure, which is sometimes referred to as the "Miller/Covin and Slevin scale" (Brown, Davidsson, and Wiklund 2001). In addition, following the suggestions of previous studies (see Wang 2008), this study adapted two items from Miller and Friesen (1983) and one item from Hurt Joseph, and Cook (1977) in order to be able to measure a firm's overall propensity for innovative behavior. In total, 12 items were included in the interview questionnaire to measure the EO construct using seven-point Likert scales.

Consistent with our previous discussion on the different perspectives on OLC and its multidimensional nature, it should not come as a surprise that the OLC construct has been captured differently in different studies. Although various theoretical studies have identified different dimensions (Crossan, Lane, and White 1999; Crossan et al. 1995; Senge 1990; Slater and Narver 1995), most of the measurement scales adopted in the empirical literature to capture OLC do not adequately reflect the many dimensions identified nor how learning (as a process of which knowledge is an outcome) can be translated between levels. As discussed earlier in our theoretical review section, Jerez-Gomez, Cespedes-Lorente, and Valle-Cabrera (2005) is one of the few studies that proposed a viable solution to this issue by considering OLC to be a latent multidimensional construct inasmuch as its full significance lies beneath the various dimensions that go toward its makeup. It is for this reason that we adopt the scale of JerezGomez, Cespedes-Lorente, and Valle-Cabrera (2005), where the OLC construct consists of 16 variables (measured on a seven-point Likert scale). According to Jerez-Gomez, Cespedes-Lorente, and Valle-Cabrera (2005), an organization should show a high degree of learning in each and every one of the dimensions defined, to be able to state that its OLC is high. These dimensions (managerial commitment, systems perspective, openness and experimentation, and knowledge transfer and integration) sum up the aspects seen as the core elements needed for an organization to develop a learning capability, and constitute the organizational learning structure of their conceptual model. Significantly, such a model recognizes the role of individual learning and its influence, direct and indirect, on the way in which organizations "learn" while also accounting for the fact that although OLC has its roots in individual learning (Senge 1990), the dynamic process that leads to OLC development goes beyond the individual learning of the organization's different members, implying moving among the different levels of learning in action and knowledge outcomes; going from the individual to the team level, and then to the organizational level and back again (Argyris and Schön 1978).

To improve the robustness of our models, we included two (firm-level) control variables. First, we controlled for organizational age, which was measured as the difference between survey year (2011) and the year in which the company was founded. The second control variable was a binary dummy taking the value of one if the firm was family-owned, and the value of zero otherwise.

As noted in our previous discussion, the present study employs three different measures 
to quantify the performance of firms. The measurement of growth consists of sales growth, market share growth, and employment growth. Growth was measured as a percentage of growth over the past two years.

\section{Data Analysis}

We follow the approach of Baker and Sinkula (2009) by viewing OLC and EO constructs as unidimensional. First, to establish that OLC and $\mathrm{EO}$ are unidimensional and that their respective variables do cross-load on each other, we conduct EFA. Next, based on EFA results and potential construct refinements, we posit a measurement model that confirms the factor structure of latent variables. Last, we employ a structural equation model (SEM) to test the relationships between two latent variables and three manifest variables pertaining to growth (sales growth, market share growth, and employment growth). The posited model is tested using maximum likelihood estimation which has been found to overcome the problems created by violations of the normality assumption (Anderson and Gerbing 1988; Bentler 1983). Both confirmatory factor analysis and the SEM estimation are performed using the Mplus 6.1 statistical program.

The mediation analysis in this study is based on the recommendations of Zhao, Lynch, and Chen (2010) who claim that the mediation specifications of Baron and Kenny (1986) are coarse and misleading. That is, as the relationship between OLC and three growth variables is not significant, based on Baron and Kenny (1986) one cannot test for partial or full mediation through EO. However, Zhao, Lynch, and Chen (2010) argue that even if there is no direct effect of the exogenous construct on the outcome, there is still a possibility for indirect-only mediation.

\section{Results}

\section{Model Constructs}

EFA with EO and OLC showed that when a two-factor solution was entered, each variable would load on its specified construct. That is, all EO variables loaded on the first factor and had factor loadings between 0.74 and 0.54 . As for OLC, we removed three variables representing OLC due to low factor loadings $(<0.40)$ (Hair, Black, Babin, Anderson, and Tatham 2006). Using the same cutoff value $(0.40)$, we determined that no variables loaded on more than factor, which denotes that cross loading is not a
Table 1

Measurement Scale Properties

$(N=350)$

\begin{tabular}{|c|c|c|}
\hline Indicator & $\begin{array}{l}\text { Completely } \\
\text { Standardized } \\
\text { Loadings }\end{array}$ & $\begin{array}{c}\text { Error } \\
\text { Variance }\end{array}$ \\
\hline $\boldsymbol{E O}$ & $\mathrm{AVE}=0.52$ & \\
\hline EO1 & $0.74^{*}$ & 0.54 \\
\hline $\mathrm{EO} 2$ & $0.74^{*}$ & 0.59 \\
\hline $\mathrm{EO} 3$ & $0.73^{*}$ & 0.60 \\
\hline $\mathrm{EO} 4$ & $0.52 *$ & 0.75 \\
\hline $\mathrm{EO} 5$ & $0.51^{*}$ & 0.66 \\
\hline EO6 & $0.68^{*}$ & 0.52 \\
\hline $\mathrm{EO} 7$ & $0.67 *$ & 0.59 \\
\hline EO8 & $0.64^{*}$ & 0.62 \\
\hline EO9 & $0.67^{*}$ & 0.59 \\
\hline EO10 & $0.67 *$ & 0.58 \\
\hline EO11 & $0.64^{*}$ & 0.60 \\
\hline EO12 & $0.60 *$ & 0.63 \\
\hline OLC & $\mathrm{AVE}=0.54$ & \\
\hline C1 & $0.60^{*}$ & 0.57 \\
\hline OLC2 & $0.55^{*}$ & 0.61 \\
\hline OLC3 & $0.70 *$ & 0.47 \\
\hline OLC4 & $0.74^{*}$ & 0.45 \\
\hline OLC5 & $0.68^{*}$ & 0.53 \\
\hline OLC6 & $0.70 *$ & 0.52 \\
\hline OLC7 & $0.65^{*}$ & 0.55 \\
\hline OLC8 & $0.59 *$ & 0.59 \\
\hline OLC9 & $0.67^{*}$ & 0.47 \\
\hline OLC10 & $0.65^{*}$ & 0.52 \\
\hline OLC11 & $0.52 *$ & 0.77 \\
\hline OLC12 & $0.51 *$ & 0.53 \\
\hline OLC13 & $0.62 *$ & 0.44 \\
\hline
\end{tabular}

*Denotes significance at the .01 level.

AVE, average variance extracted; OLC, organizational learning capability, EO, entrepreneurial orientation.

concern here. The refined OLC construct consisted of 13 variables whose loadings ranged between 0.74 and 0.48 .

Next, we assessed the reliability and construct validity of manifest variables representing the two exogenous constructs (OLC and EO). First, we used Cronbach's alpha to measure unidimensionality of the key constructs (OLC and EO). Both constructs had an acceptable internal consistency based on the 0.70 threshold value of Nunnally (1978) (Table 1). That is, OLC and EO had alpha values of 0.88 and 0.88 , respectively, which 


\section{Table 2}

Descriptive Statistics and Correlations

\begin{tabular}{lccccccc}
\hline Variables & Mean & S.D. & $\mathbf{1}$ & $\mathbf{2}$ & $\mathbf{3}$ & $\mathbf{4}$ & $\mathbf{5}$ \\
\hline 1. EO & 4.50 & 1.18 & 1 & & & & \\
2. OLC & 4.49 & 1.04 & $0.60^{*}$ & 1 & & & \\
3. Sales Growth & 5.64 & 19.82 & $0.25^{*}$ & 0.15 & 1 & & \\
4. Market Share Growth & 5.14 & 15.03 & $0.11^{*}$ & -0.01 & $0.67^{*}$ & 1 & \\
5. Employment Growth & 2.43 & 14.34 & 0.04 & 0.02 & $0.36^{*}$ & $0.37^{*}$ & 1 \\
& & & & & & & \\
\hline
\end{tabular}

*Denotes significance at the .05 level.

OLC, organizational learning capability; EO, entrepreneurial orientation; S.D., standard deviation.

show that both constructs are unidimensional. We also checked for composite reliability (Fornell and Larcker 1981). Both constructs had acceptable composite reliability $(\mathrm{EO}=.89$; OLC $=.89)$. Next, we checked for construct validity which is disclosed through convergent and discriminant validity. Convergent validity can be detected from the $t$ value of each indicator (Anderson and Gerbing 1988; Bagozzi and Lynn 1982). As can be seen in Table 1, all indicator loadings had significant $t$ values $(p<.01)$. We used Average Variance Extracted (AVE) as another measure to check for convergent validity (Fornell and Larcker 1981). Both constructs had AVE values of over 0.50 (see Table 1) which offered support for convergent validity. We also followed up by constraining the correlation parameter between the constructs at 1.0 and then observing the Chi-square difference values for the unconstrained and constrained models. Our results show that the Chi-square value for unconstrained model $\left(\chi^{2}=419.55\right.$, $d f=274)$ was significantly lower than that of the constrained model $\left(\chi^{2}=1,206.72, d f=386\right)$. The significant Chi-square difference between the two models demonstrated that discriminant validity held for the measurement model.

While the Chi-square value for the measurement model was significant $\left(\chi^{2}=419.55\right.$, $d f=274, p<.01)$, we followed Jöreskog and Sörbom's (1993, p. 309) note that "since chisquare is $N-1$ times the minimum value of the fit function, the chi-square test tends to be large in large samples." As a result, to evaluate our model, we looked at commonly used incremental goodness-of-fit indices: the Tucker-Lewis Index (TLI) and the comparative fit index (CFI). The TLI value of 0.95 for our model implies that the proposed measurement model demonstrates a good fit to data. The CFI value produced by our measurement model (0.94) denotes a good fit (Bentler 1992). Next, we checked residual measures of the model. The standardized root mean square residual (SRMR) value for the measurement model was 0.05 which is indicative of a well-fitting model as suggested by the threshold value of 0.05 (Byrne 1998). The other residual measure, the root means error of approximation (RMSEA) value was 0.05 which is considered satisfactory (Hair et al. 2006).

As can be seen in Table 2, EO and OLC had similar means. The same can be said about sales growth and market share growth. Sales growth had the highest mean and highest standard deviation among three growth measures. The results also show that OLC and EO were highly correlated (0.60). EO was significantly correlated with sales growth and market share growth. However, OLC did not have significant correlations with the three performance measures.

\section{Hypothesis Testing}

This section investigates two structural models. The first model (Model 1) is based on the depiction of the conceptual model in Figure 1 and hypotheses which make up the empirical side of this study. In Model 1, OLC is an exogenous construct, EO is a mediator and the three growth measures are dependent variables. This is our main model which we use to test Hypotheses 1, 2, 3a, and 4a. Model 2 is a competing structural model where $\mathrm{EO}$ is an exogenous construct, whereas OLC is a mediator between EO and growth. Model 2 is employed to test Hypotheses $3 \mathrm{~b}$ and $4 \mathrm{~b}$. It should be noted that organizational age and firm type are used as control variables in both models. As can be seen in Table $3, \chi^{2}$ value is significant, which could 


\section{Table 3}

\section{Structural Equation Results and Mediation Analysis}

\begin{tabular}{l} 
Model 1 \\
\hline$\chi^{2}=422.73$ \\
CFI $=0.92$ \\
TLI $=0.92$ \\
RMSEA $=0.05$ \\
SRMR $=0.05$ \\
\hline
\end{tabular}

Hypothesized Path

\section{Model 1}

H1: EO $\rightarrow$ SALES GROWTH

H1: EO $\rightarrow$ MARKET SHARE GROWTH

H1: EO $\rightarrow$ EMPLOYMENT GROWTH

$\mathrm{H} 2:$ OLC $\rightarrow$ SALES GROWTH

H2: OLC $\rightarrow$ MARKET SHARE GROWTH

H2: OLC $\rightarrow$ EMPLOYMENT GROWTH

$\mathrm{H} 3 \mathrm{a}: \mathrm{OLC} \rightarrow \mathrm{EO}$

H4a: OLC $\rightarrow$ EO $\rightarrow$ SALES GROWTH

H4a: OLC $\rightarrow$ EO $\rightarrow$ MARKET SHARE GROWTH

H4a: OLC $\rightarrow$ EO $\rightarrow$ EMPLOYMENT GROWTH

\section{Model 2}

H3b: EO $\rightarrow$ OLC

H4b: EO $\rightarrow$ OLC $\rightarrow$ SALES GROWTH

H4b: EO $\rightarrow$ OLC $\rightarrow$ MARKET SHARE GROWTH

H4b: EO $\rightarrow$ OLC $\rightarrow$ EMPLOYMENT GROWTH

\begin{tabular}{c} 
Model 2 \\
\hline$\chi^{2}=422.73$ \\
\hline CFI $=0.92$ \\
\hline TLI $=0.92$ \\
\hline RMSEA $=0.05$ \\
SRMR $=0.05$
\end{tabular}

Direct Effect Indirect Effect Supported

$\begin{array}{ccc}0.24(3.01)^{* * *} & - & \text { YES } \\ 0.16(1.99)^{*} & - & \text { YES } \\ -0.02(0.78) & - & \text { NO } \\ -0.01(-0.09) & - & \text { NO } \\ -0.13(-1.72) & - & \text { NO } \\ 0.04(0.53) & - & \text { NO } \\ 0.60(14.66)^{* * *} & & \text { YES } \\ - & 0.14(3.13) * * & \text { YES } \\ - & 0.10(2.18)^{*} & \text { YES } \\ - & -0.01(-0.28) & \text { NO } \\ & - & \text { YES } \\ 0.49(8.08)^{* *} & -0.00(-0.09) & \text { NO } \\ - & -0.06(-1.70) & \text { NO } \\ - & 0.02(0.52) & \text { NO }\end{array}$

$* p \leq .05$

$* * p \leq .01$

$T$-values are shown in parentheses.

be attributed to large sample size $(N=350)$. The evaluation of fit indices reveals that the model achieves a good fit (CFI $=0.92$, TLI $=0.92$, RMSEA $=0.05$, SRMR $=0.05)($ Table 3$)$.

$\mathrm{H} 1$ predicted a significant positive relationship between EO and growth (sales growth, market share growth, and employment growth). This hypothesis is only partially supported. The results in Table 3 indicate that $\mathrm{EO}$ has a positive and significant influence on sales growth after controlling for organizational age and firm type $(t=3.01, p<.003)$. Similarly, the relationship between EO and market share is significant and positive, which is also consistent with $\mathrm{H} 1$ $(t=1.99, p<.044)$. Last, we found that there is no significant relationship between EO and employment growth. In the meantime, organizational age had a significant negative relationship with all three growth variables. Conversely, firm type is not significantly related with growth variables. The partial support for $\mathrm{H} 1$ is consistent with previous studies which find a positive significant relationship between EO and growth (Casillas, Moreno, and Barbero 2010; Covin, Green, and Slevin 2006; Wang and Altinay 2012).

$\mathrm{H} 2$ predicted that there is a direct positive effect of OLC on growth (sales growth, market share growth, and employment growth). Results show that the relationship between OLC and growth measures was not significant in all three 
cases. Consequently, $\mathrm{H} 2$ is not supported, which contradicts the findings of Aragon-Correa, Garciamorales, and Cordonpozo (2007).

$\mathrm{H} 3 \mathrm{a}$ predicted that OLC has a positive and significant influence on EO. The analysis supports this proposition $(t=14.16, p<.000)$. In addition, we find that organizational age is negatively related to $\mathrm{EO}$. The second control, firm type, does not have significant effect on EO.

H4a predicted that EO mediates the relationship between OLC and the three growth measures. As the relationship between OLC and three growth measures was not significant, we can only test for indirect-only mediation (Zhao, Lynch, and Chen 2010). That is, we investigate the paths from OLC to EO, and EO to growth to confirm whether there is an indirect-only mediation effect of OLC on growth. The mediation analysis showed that the indirect effect of OLC on sales growth was $0.14 \quad(t=3.13$, $p<.003)$. This finding lends support for $\mathrm{H} 4 \mathrm{a}$. Similarly, EO mediates the relationship between OLC and market share growth $(0.10, t=2.18$, $p<.047$ ), which again is consistent with H4a. As neither OLC nor EO had a significant relationship with employment growth, H4a was not supported. We conclude that indirect-only mediation is present based on sales growth and market share growth. This finding sheds some light into the intriguing effect of OLC on organizational performance, particularly in a single industry setting (i.e., services). That is, we report that firms with greater learning capability are able to identify the changing consumer needs and wants better than their competitors, leading to better organizational performance. In other words, the identification of these needs is a learning capability matter. Conversely, the provision of products and services that customers expect is a fruit of EO which shows that OLC drives business performance via EO. Our results are in concert with the study of Aragon-Correa, Garciamorales, and Cordonpozo (2007) who showed that innovation mediated the relationship between OLC and performance. In their study, the indirect effect of OLC on performance was higher than its direct effect (0.41 vs. 0.24$)$.

We used a competing model (Model 2 in Figure 2), where EO was an exogenous construct. First, we looked at the relationship between EO and OLC. Then, we investigated whether OLC mediates the relationship between $\mathrm{EO}$ and growth (sales growth, market share growth, and employment growth). $\mathrm{H} 3 \mathrm{~b}$ predicted a positive relationship between EO and OLC after control- ling for organizational age and firm type. As can be seen in Table 3, results show that EO is significantly and positively related with OLC $(t=8.08, p<.000)$. This finding offers support for H3b. It should be noted that the path coefficient in $\mathrm{H} 3 \mathrm{~b}(0.49)$ is lower than $\mathrm{H} 3 \mathrm{a}(0.60)$, which denotes that OLC is a stronger determinant of EO after we account for the effects of control variables and outcome variables. $\mathrm{H} 4 \mathrm{~b}$ predicted that OLC is a mediator between EO and growth. As can be seen in Table 2, the indirect effect of $\mathrm{EO}$ on three growth variables was not significant, which leads us to conclude that OLC does not mediate the relationship between $\mathrm{EO}$ and growth measures.

\section{Discussion}

The findings of this study offer interesting insights into the management of SMEs. First, consistent with the findings of previous research (Casillas, Moreno, and Barbero 2010; Covin, Green, and Slevin 2006; Wang and Altinay 2012), we find a positive relationship between the EO and SME growth. Firms which actively innovate (new products and services), act proactively to grasp market opportunities, and undertake risks, tend to perform better. Interestingly, however, this positive relationship between EO and growth is evident between $\mathrm{EO}$ and market share and sales growth measures, but not between EO and employment growth. This finding contradicts the findings reported by Madsen (2007) who undertook a longitudinal analysis to understand the growth of Norwegian SMEs and found that there is a positive relationship between EO and employment growth. This conflicting evidence could be due to the differences of the contexts in which the SMEs of these two studies operate. The sample of our study is primarily comprised of SMEs from labor intensive industries, namely, services and retailing. It could well be that the SMEs in these industries keep their labor force at the minimal level in order to minimize the cost of their operations. In addition, in the case of small businesses on the island, there is a tendency to employ family members or friends as voluntary workforce rather than officially increasing the number of employees, which would obviously increase the cost of operations. Moreover, the type of organizations in our sample alongside the lack of exporting capability, inevitably constrain further the capacity of such organizations to employ more staff. Finally, returning to the point made 
by Ireland, Reutzel, and Webb (2005) about the impact of EO on job creation, it needs to be emphasized that this tends to be a measure employed by policymakers and not necessarily by entrepreneurs/owner-managers.

Second, unlike previous research (Bontis, Crossan, and Hulland 2002; Prieto and Revilla 2006; Tippins and Sohi 2003), this study shows that there is no relationship between OLC and growth, irrespective of the growth measure used. This could be due to the fact that the cause-and-effect relationship between OLC and performance is not necessarily straightforward; the influence of OLC on growth occurs over many steps and is very difficult to define (Yeo 2003). In addition, as Prieto and Revilla (2006) point out, organizational outcomes such as better performance can be influenced by many other factors such as an organization's environment, leadership, and organizational culture. After all, as noted in the introduction, the North Cyprus economy can be considered as a "closed" economy. Its opportunities to market products and services are limited to only two markets: Turkey and North Cyprus. On one hand, this state of affairs protects the country's economic environment from the global economic crisis, thereby reducing turbulence and the degree of higher competitiveness that follows. On the other hand, it creates demand uncertainty. In addition, there is an "over protective" government and public sector involvement in the economy. The positive relationships between $\mathrm{EO}$ and growth could be explained by the government and public sector's involvement where they act as suppliers of support (information, financial capital, tax exemptions and subsidies, etc.) for the production of products and services and at the same time they are the largest buyers of products and services (Katircioglu 2010; Mehmet 2010).

Third, the findings of this study provide support to the view that there is a two way interaction between OLC and EO (see Bell, Whitwell, and Lukas 2002; Hakala and Kohtamaki 2011). However, it needs to be emphasized that in this study the influence of OLC on EO stems from the latent dimensions underlying the framework we adopted (Jerez-Gomez, Cespedes-Lorente, and Valle-Cabrera 2005), from which the OLC measurement scale was developed. In this respect, a fundamental contribution of our findings can be identified in the OLC conditions that influence EO (which obviously differ from those of other studies which employ a different OLC construct, e.g., Alegre and Chiva 2013). These conditions, linked to the framework's dimensions, are exemplified by managerial commitment toward learning (leadership support), a system approach that builds upon and transcends individual learning endeavors, an attitude welcoming openness toward new ideas and experimentation, and the establishment of "barrierless" processes of knowledge transfer and integration. This suggests that EO and OLC need to be related to the strategic goals of the SMEs and need to be aligned in order for the SMEs to take full advantage of market opportunities. This view also adds to the arguments of Wiklund and Shepherd (2005) and Baker and Sinkula (2009) who argue that SMEs need to adopt a combined approach to their strategic postures, as relying only on one-OLC or EOcould create temporary advantages but not sustainable competitive advantages. This insight is particularly relevant for SMEs often competing in "narrow markets," such as North Cyprus where potential growth can be limited, but competitive advantage is essential. SMEs, therefore, need to adopt a more strategic approach to management and develop strong and effective learning mechanisms that could stimulate entrepreneurial activities. EO can be developed over time through consistent investment in resources that could enhance learning capability. Likewise, SMEs need to engage in entrepreneurial activities and create platforms for exploration and experimentation of new ideas to broaden their scope for learning and pursue new business endeavors.

Finally, and most importantly, this study tested the mediating effects of both the EO and OLC on SME growth. Unlike previous research (Covin, Green, and Slevin 2006; Wang 2008), the findings of this study showed that the EO-SME growth relationship is not mediated by OLC. While the lack of support for the mediation effect of OLC on performance may seem surprising, it should be noted once again that our OLC construct differs from other studies that look at the mediating effect of OLC on performance (e.g., Wang 2008). However, we find that the OLCSME growth relationship is mediated by EO; that is, OLC has a positive impact on EO which, in turn, has a positive impact on SME growth. This finding provides empirical support to the arguments of Aragon-Correa, Garciamorales, and Cordonpozo (2007) and Ar and Baki (2011) who identified the mediating role of EO in the OLCperformance relationship. This finding also corroborates the views of Hakala and Kohtamaki (2011) and Wiklund and Shepherd (2005) who 
argue that a holistic and strategic approach to understanding SME growth is crucial because the orientations complement each other leading to improved SME growth. SMEs that combine EO and OLC are likely to perform even better than firms adopting only one. Therefore, SMEs need to align EO and OLC and achieve congruence between these orientations in order to generate performance enhancing behaviors.

\section{Conclusions}

This paper makes two distinct and timely contributions to the small business management literature. First, this paper is one of those few studies adopting a strategic management perspective to understanding the combined and simultaneous effects of orientations on various measures of growth in a small business context. Previous research has identified six distinct approaches to studying SME growth (Dobbs and Hamilton 2007). However, recognizing the deficiencies of each approach, researchers (Baker and Sinkula 2009; Wang 2008) called for the adoption of a more strategic approach to understanding SME growth encouraging further research into the combined and simultaneous effects of orientations on growth in a small business context. Responding to these calls, this study investigated SME growth through analyzing the combined effects of EO and OLC on SME growth measures in terms of sales growth, market share growth, and employment growth. Reporting on 350 SMEs, this study developed a model that uses a multiconstruct framework and systematically examined the influence of EO and OLC on SME growth. Our results demonstrate that there is a positive relationship between EO and growth when the latter is measured in terms of sales growth and market share growth, but not in terms of employment growth. The findings of this study also demonstrated that there is a positive, bilateral relationship between OLC and EO in the context of SMEs. In particular, this study's findings suggest that an aligned and congruent EO and OLC are essential for the SMEs to take advantage of market opportunities. More specifically, OLC appears to be an important contributor to the proactive entrepreneurial engagements and sustainable growth of SMEs. This finding denotes that EO and growth of SMEs could be stimulated and facilitated through acquiring and exploiting knowledge thorough various learning mechanisms and channels in SMEs.
Second, the study investigated the mediating effects of EO and OLC on SME growth, a research avenue where there is a dearth of empirical studies. In contrast to the arguments of Wang (2008) and Covin, Green, and Slevin (2006), this study found that the EO-Growth relationship is not mediated by OLC in SMEs. However, when there are entrepreneurial engagements, OLC augments EO and thus affects growth positively. Such a finding and contribution is important because this study demonstrates that EO facilitates OLC through broadening the scope of SMEs for learning and developing an adaptable and flexible approach to the exploitation of market opportunities. Hence, it is through EO that SMEs maximize the impact of OLC on firm performance.

While acknowledging some limitations of our study, we also offer recommendations for further research. First, as in this study the survey data are cross sectional in nature, it was not possible to capture the dynamic interplay between OLC and growth. We recommend that future work makes use of longitudinal data in order to better assess the relationship between OLC and various measures of growth. Second, other measures of organizational growth such as profitability and return on investment could be considered. Third, although our study controlled for some firm characteristics, another novelty that is acutely needed at the empirical level is the utilization of contextual and environmental variables as moderators or control variables in measuring the relationship between OLC and growth. While Wang (2008) considered the four strategic orientations of Miles and Snow (1978) more research is needed to include various contingencies such as environmental uncertainty, environmental munificence, the state of the economy, and the life cycle of the industry(ies) under examination. Finally, notwithstanding the generalizability of our results, it should also be acknowledged that the North Cyprus context, particularly in terms of cultural connotations, may bear some influence on the strategic and learning orientations of the businesses in our sample, their business conduct and attendant behaviors. This caveat calls for further research across different countries and cultural contexts.

\section{References}

Alegre, J., and R. Chiva (2013). "Linking Entrepreneurial Orientation and Firm Performance: The Role of Organizational Learning 
Capability and Innovation Performance," Journal of Small Business Management 51, 491-507.

Altinay, L., and E. Altinay (2006). "Determinants of Ethnic Minority Entrepreneurial Growth in the Catering Sector," The Service Industries Journal 26(2), 203-221.

Anderson, J. C., and D. W. Gerbing (1988). "Structural Equation Modeling in Practice: A Review and Recommended Two-Step Approach," Psychological Bulletin 103(3), 411-423.

Ar, M. I., and B. Baki (2011). "Antecedents and Performance Impacts of Product versus Process Innovation," European Journal of Innovation Management 41(2), 172-206.

Aragon-Correa, J. A., V. Garciamorales, and E. Cordonpozo (2007). "Leadership and Organizational Learning's Role on Innovation and Performance," Industrial Marketing Management 36(3), 349-359.

Aragon-Sanchez, A., and G. Sanchez-Marin (2005). "Strategic Orientation, Management Characteristics, and Performance: A Study of Spanish SMEs," Journal of Small Business Management 43(3), 287-308.

Argyris, C., and D. A. Schön (1978). Organizational Learning: A Theory of Action Perspective. Reading, MA: Addison-Wesley.

Baker, W. E., and J. M. Sinkula (1999). "The Synergistic Effect of Market Orientation and Learning Orientation on Organizational Performance," Journal of the Academy of Marketing Science 27(4), 411-427.

- (2009). "The Complementary Effects of Market Orientation and Entrepreneurial Orientation on Profitability in Small Businesses," Journal of Small Business Management 47(4), 443-464.

Bagozzi, R. P., and W. P. Lynn (1982). "Representing and Testing Organizational Theories: A Holistic Construal," Administrative Science Quarterly 27(3), 459-489.

Baldwin, J., W. Chandler, C. Le, and T. Papailiadis (1994). "Strategies for Success: A Profile of Growing Small and MediumSized Enterprises," Catalogue No. 61-523RE. Ottawa, Canada: Statistics Canada.

Barkham, R., G. Gudgin, M. Hart, and E. Hanvey (1996). The Determinants of Small Firm Growth: An Inter-Regional Study in the UK, 1986-90. London: Jessica Kingsley.

Baron, R. M., and D. A. Kenny (1986). "The Moderator-Mediator Variable Distinction in Social Psychological Research: Conceptual,
Strategic, and Statistical Considerations," Journal of Personality \& Social Psychology 51, 1173-1182.

Basu, A., and A. Goswami (1999). "South Asian Entrepreneurship in Great Britain: Factors Influencing Growth," International Journal of Entrepreneurial Behavior and Research 5(5), 251-275.

Bell, S. J., G. J. Whitwell, and B. A. Lukas (2002). "Schools of Thought in Organizational Learning," Journal of the Academy of Marketing Science 30(1), 70-86.

Bentler, P. M. (1983). "Some Contributions to Efficient Statistics in Structural Models: Specification and Estimation of Moment Structures," Psychometrika 48(4), 493-517. (1992). "On the Fit of Models to Covariances and Methodology to the Analysis of Covariance Structures," Psychological Bulletin 112(3), 400-404.

Birley, S., and P. Westhead (1990). "Growth and Performance Contrasts Between 'Types' of Small Firms," Strategic Management Journal 11(7), 535-557.

Bontis, N., M. Crossan, and J. Hulland (2002). "Managing an Organizational Learning System by Aligning Stocks and Flows," Journal of Management Studies 39(4), 437-469.

Brown, T. H., P. Davidsson, and J. Wiklund (2001). "An Operationlisation of Stevenson's Conceptualization of Entrepreneurship as Opportunity-Based Firm Behavior," Strategic Management Journal 22, 953-968.

Byrne, N. M. (1998). Structural Equation Modeling with LISREL, PRELIS, and SIMPLIS: Basic Concepts, Applications, and Programming. Mahwah, NJ: Lawrence Erlbaum Associates, Inc.

Casillas, J. C., A. M. Moreno, and J. L. Barbero (2010). "A Configurational Approach of the Relationship Between Entrepreneurial Orientation and Growth of Family Firms," Family Business Review 23(1), 27-44.

Chiva, R., J. Alegre, and R. Lapiedra (2007). "Measuring Organizational Learning Capabilityamong Workforce," International Journal of Manpower 28(3/4), 224-242.

Cohen, M., and L. Sproull (1996). Organizational Learning. London: Sage.

Cope, J. (2005). "Toward a Dynamic Learning Perspective of Entrepreneurship," Entrepreneurship Theory and Practice 29(4), 373-397.

Covin, J., and G. T. Lumpkin (2011). "Entrepreneurial Orientation Theory and Research: Reflections on a Needed 
Construct," Entrepreneurship Theory and Practice 35(5), 855-872.

Covin, J. G., and D. P. Slevin (1989). "Strategic Management of Small Firms in Hostile and Benign Environments," Strategic Management Journal 10(1), 75-87.

(1991). "A Conceptual Model of Entrepreneurship as Firm Behavior," Entrepreneurship Theory and Practice 16(1), 7-25.

Covin, J., K. M. Green, and D. Slevin (2006). "Strategic Process Effects on the Entrepreneurial Orientation Sales Growth Rate Relationship," Entrepreneurship Theory and Practice 30(1), 57-81.

Crossan, M., H. Lane, and R. White (1999). "An Organizational Learning Framework: From Intuition to Institution," Academy of Management Review 24(3), 522-537.

Crossan, M., H. Lane, R. White, and L. Djurfeldt (1995). "Organizational Learning: Dimensions for a Theory," International Journal of Organizational Analysis 3(4), 337-360.

De Jong, J. P. J., and P. A. M. Vermuelen (2006). "Determinants of Product Innovation in Small Firms: A Comparison Across Industries," International Small Business Journal 24(6), 587-609.

Deakins, D., and M. Freel (1998). "Entrepreneurial Learning and the Growth process in SMEs," The Learning Organisation 5(3), 144-155.

Dess, G. G., and G. T. Lumpkin (2005). "The Role of Entrepreneurial Orientation in Stimulating Effective Corporate Entrepreneurship," Academy of Management Executive 19(1), 147-156.

DiBella, A. J., E. C. Nevis, and J. M. Gould (1996). "Understanding Organizational Learning Capability," Journal of Management Studies 33(3), 361-379.

Dobbs, M., and R. T. Hamilton (2007). "Small Business Growth: Recent Evidence and New Directions," International Journal of Entrepreneurial Behavior \& Research 13(5), 296322.

Edmondson, A. C. (2002). "The Local and Variegated Nature of Learning in Organizations: A Group-Level Perspective," Organization Science 13(2), 128-146.

Escriba-Esteve, A., L. Sanchez-Peinado, and E. Sanchez-Peinado (2008). "Moderating Influences on the Firm's OrientationPerformance Relationship," International Small Business Journal 26(4), 463-489.
(2009). "The Influence of Top Management Teams in the Strategic Orientation and Performance of Small and Medium-sized Enterprises," British Journal of Management 20, 581-597.

Fadahunsi, A., D. Smallbone, and S. Supri (2000). "Networking and Ethnic Minority Enterprise Development: Insights from a North London Study," Journal of Small Business and Enterprise Development 7(3), 228-240.

Fischer, E., and R. Reuber (2002). "Industrial Clusters and BDS for SMEs in Developing Countries, Competitiveness Strategy and Industrial Performance in Developing Countries: A Manual for Policy Analysis. London: Routledge.

Floyd, W. S., and B. Wooldridge (1999). "Knowledge Creation and Social Networks in Corporate Entrepreneurship: The Renewal of Organizational Capability," Entrepreneurship Theory and Practice 23(3), 123-143.

Fornell, C., and D. F. Larcker (1981). "Evaluating Structural Equation Models with Unobservable Variables and Measurement Error," Journal of Marketing Research 18(1), 39-50.

Garcia-Morales, V. J., F. J. Llorens-Montes, and A. J. Verdu-Jover (2007). "Influence of Personal Mastery on Organizational Performance through Organizational Learning and Innovation in Large Firms and SMEs," Technovation 27(9), 547-568.

Garvin, D. A. (1993). "Building a Learning Organization," Harvard Business Review 71(4), 78-91.

Gibb, A. (1997). "Small Firms' Training and Competitiveness, Building Upon Small Business as a Learning Organization," International Small Business Journal 15(3), 13-29.

Goh, S., and G. Richards (1997). "Benchmarking the Learning Capacity of Organizations," European Management Journal 15(5), 575-583.

Grant, R. M. (1996). "Prospering in Dynamically-Competitive Environments: Organizational Capability as Knowledge Integration," Organization Science 7(4), 375-387.

Grinstien, A. (2008). "The Relationship Between Market Orientation and Alternative Strategic Orientations: A Meta-analysis," European Journal of Marketing 42(1/2), 115-134. 
Guzzo, R. A., R. D. Jette, and R. A. Katzell (1985). "The Effects of Psychologically Based Intervention Programs on Worker Productivity," Personnel Psychology 38, 275-292.

Hair, J. F., W. C. Black, B. J. Babin, R. E. Anderson, and R. L. Tatham (2006). Multivariate Data Analysis. Upper Saddle River, NJ: Pearson Prentice Hall.

Hakala, H. (2011). "Strategic Orientations in Management Literature: Three Approaches to Understanding the Interaction Between Market, Technology, Entrepreneurial and Learning Orientations," International Journal of Management Reviews 13, 199-217.

Hakala, H., and M. Kohtamaki (2011). "Configurations of Entrepreneurial-Customer and Technology Orientation: Differences in Learning and Performance of Software Companies," International Journal of Entrepreneurial Behavior and Research 17(1), 64-81.

Hitt, M. A., R. D. Ireland, S. M. Camp, and D. L. Sexton (2001). "Strategic Entrepreneurship: Entrepreneurial Strategies for Wealth Creation," Strategic Management Journal 22(Special Issue), 479-491.

Howells, K., and B. Krivokapic-Skoko (2010). "Constraints on Female Women's Entrepreneurship in Northern Cyprus, KADIN WOMAN 2000," Special Issue: Entrepreneurship: Multi-Disciplinary Perspectives, Vol. 8, No. 1. Famagusta, Cyprus: Eastern Mediterranean University.

Huber, G. P. (1991). “Organizational Learning: The Contributing Processes and the Literatures," Organization Science 2(1), 88-115.

Hult, G. T., and O. C. Ferrell (1997). "Global Organizational Learning Capacity in Purchasing: Construct and Measurement," Journal of Business Research 40, 97-111.

Hult, G. T., and D. Ketchen (2001). "Does Market Orientation Matter? A Test of the Relationship Between Positional Advantage and Performance," Strategic Management Journal 22(9), 899-906.

Hurt, H. T., K. Joseph, and C. D. Cook (1977). "Scales for the Measurement of Innovativeness," Human Communication Research 4(1), 58-65.

Ireland, R. D., M. A. Hitt, and D. G. Sirmon (2003). "A Model of Strategic Entrepreneurship: The Construct and Its Dimensions," Journal of Management 29, 963-989.
Ireland, R. D., C. R. Reutzel, and J. W. Webb (2005). "Entrepreneurship Research in AMJ: What Has Been Published, and What Might the Future Hold?" Academy of Management Journal 48(4), 556-564.

Jerez-Gomez, P., J. Cespedes-Lorente, and R. Valle-Cabrera (2005). "Organizational Learning Capability: A Proposal of Measurement," Journal of Business Research 58, 715-725.

Jöreskog, K. G., and D. Sörbom (1993). LISREL 8: Structural Equation Modeling with the SIMPLIS Command Language. Hillsdale, NJ: Lawrence Erlbaum Associates.

(1996). LISREL 8: User's Reference Guide. Mooresville, IN: Scientific Software, Inc.

Katircioglu, S. (2010). "Trade and Growth in a Non-Recognised Small Island State: Evidence from the Turkish Republic of Northern Cyprus," Journal of Business Economics and Management 11, 112-130.

Keh, H. T., T. T. M. Nguyen, and H. P. Ng (2007). "The Effects of Entrepreneurial Orientation and Marketing Information on the Performance of SMEs," Journal of Business Venturing 22(4), 592-611.

Koc, T. (2007). "Organizational Determinants of Innovation Capacity in Software Companies," Computers \& Industrial Engineering 53(3), 373-385.

Kofman, F., and F. M. Senge (1993). "Communities of Commitment: The Heart of Learning Organizations," Organizational Dynamics 22(2), 4-24.

Leonard-Barton, D. (1992). "The Factory as a Learning Laboratory," Sloan Management Review 34(1), 23-38.

Li, Y., J. Huang, and M. Tsai (2009). "Entrepreneurial Orientation and Firm Performance: The Role of Knowledge Creation Process," Industrial Marketing Management 38(4), 440-449.

Lumpkin, G. T., and G. G. Dess (1996). "Clarifying the Entrepreneurial Orientation Construct and Linking It to Performance," Academy of Management Review 21, 135-172.

Madsen, E. L. (2007). "The Significance of Sustained Entrepreneurial Orientation on Performance of Firms - A Longitudinal Analysis," Entrepreneurship and Regional Development 19(2), 185-204.

McAdam, R., G. Armstrong, and B. Kelly (1998). "Investigation of the Relationship Between Total Quality and Innovation: A 
Research Study Involving Small Organizations," European Journal of Innovation Management 1(3), 139-147.

Mehmet, O. (2010). Sustainability of Microstates: The Case of North Cyprus. Salt Lake City, UT: University of Utah Press.

Miles, M. P., and D. R. Arnold (1991). "The Relationship between Marketing Orientation and Entrepreneurial Orientation," Entrepreneurship Theory and Practice 15(4), 49-65.

Miles, R. E., and C. C. Snow (1978). Organizational Strategy, Structure and Process. New York: McGraw-Hill.

Miller, D. (1983). "The Correlates of Entrepreneurship in Three Types of Firms," Management Science 29, 770-791.

___ (1996). "Preliminary Typology of Organizational Learning: Synthesizing the Literature," Journal of Management 22(3), 485-505.

Miller, D., and P. H. Friesen (1983). "StrategyMaking and Environment: The Third Link," Strategic Management Journal 4, 221-235.

Morgan, R. E., and C. A. Strong (2003). "Business Performance and Dimensions of Strategic Orientation," Journal of Business Research 56(3), 163-176.

Morris, M. H., and G. W. Paul (1987). "The Relationship Between Entrepreneurship and Marketing in Established Firms," Journal of Business Venturing 2, 247-259.

Nahapiet, J., and S. Goshal (1998). "Social Capital, Intellectual Capital and the Organizational Advantage," Academy of Management Review 32(2), 242-266.

Naman, J. L., and D. P. Slevin (1993). "Entrepreneurship and The Concept of Fit: A Model and Empirical Test," Strategic Management Journal 14(2), 135-152.

Nicolini, D., and M. Meznar (1995). "The Social Construction of Organizational Learning: Conceptual and Practical Issues in the Field," Human Relations 48(7), 727-746.

Nonaka, I. (1994). "Dynamic Theory of Organizational Knowledge Creation," Organizational Science 5(1), 14-37.

Nonaka, I., and H. Takeuchi (1995). The Knowledge-Creating Company. New York: Oxford University Press.

Nunnally, J. C. (1978). Psychometric Theory. New York: McGraw-Hill.

Palacios-Marques, D., D. Ribeiro-Soriano, and I. Gil-Pechuan (2011). "The Effect of Learning Based Distinctive Competencies on Firm Performance: A Study of Spanish Hospitality
Firms," Cornell Hospitality Quarterly 52(2), 102-110.

Parnell, A. J. (2013). "Uncertainty, Generic Strategy, Strategic Clarity, and Performanceof Retail SMEs in Peru, Argentina, and the United States," Journal of Small Business Management 51(2), 215-234.

Perks, J. K. (2006). "Influences on Strategic Management Styles Among Fast Growth Medium-sized Firms in France and Germany," Strategic Change 15(3), 153-164.

Podsakoff, P. M., and D. W. Organ (1986). "Self-Reports in Organizational Research: Problems and Prospects," Journal of Management 12(2), 531-544.

Popper, M., and R. Lipshitz (2000). "Organizational Learning: Mechanism, Culture and Feasibility," Management Learning 31(2), 181-196.

Prieto, I., and E. Revilla (2006). "Assessing the Impact of Learning Capability on Business Performance: Empirical Evidence from Spain," Management Learning 37(4), 499-522.

Reijonen, H., T. Laukkanen, R. Komppula, and S. Tuominen (2012). "Are Growing SMEs More Market-Oriented and Brand Oriented?" Journal of Small Business Management 50(4), 699-716.

Rue, L., and N. Ibrahim (1998). "The Relationship Between Planning Sophistication and Performance in Small Businesses," Journal of Small Business Management 36(4), 24-33.

Senge, P. M. (1990). The Fifth Discipline: The Art and Practice of the Learning Organization. New York: Doubleday.

Siguaw, J. A., P. M. Simpson, and C. A. Enz (2006). "Conceptualizing Innovation Orientation: A Framework for Study and Integration of Innovation Research," Journal of Product Innovation Management 23(6), 556-574.

Sinkula, J. M. (1994). "Market Information Processing and Organizational Learning," Journal of Marketing 58(1), 35-45.

Sinkula, J. M., W. Baker, and T. Noordewier (1997). "A Framework for Market-based Organizational Learning: Linking Values, Knowledge, and Behavior," Journal of the Academy of Marketing Science 25(4), 305-319.

Slater, S. F., and J. C. Narver (1995). "Market Orientation and the Learning Organization," Journal of Marketing 59(3), 63-74.

Soo, C. W., T. W. Devinney, and D. F. Midgley (2004). "The Role of Knowledge Quality in Firm Performance," in Organizations as Knowledge Systems. Knowledge, Learning and 
Dynamic Capabilities. Eds. H. Tsoukas and N. Mylonopoulus. London: Palgrave Macmillan.

Spicer, P. D., and E. Sadler-Smith (2006). "Organizational Learning in Smaller Manufacturing Firms," International Small Business Journal 24(2), 133-158.

Stevenson, H. H., and J. C. Jarillo (1990). "A Paradigm of Entrepreneurship: Entrepreneurial Management," Strategic Management Journal 11, 17-27.

Tanova, C. (2003). "Firm Size and Recruitment: Staffing Practices in Small and Large Organizations in North Cyprus," Career Development International 8(2), 107-114.

Theriou, N. G., and D. P. Chatzoglou (2009). "Exploring the Best HRM PracticesPerformance Relationship: An Empirical Approach," Journal of Workplace Learning 21(8), 614-646.

Tippins, M. J., and R. Sohi (2003). "IT Competency and Firm Performance: Is Organizational Learning a Missing Link?" Strategic Management Journal 24, 745-761.

Ulrich, D., T. Jick, and M. A. Glinow (1993). "High-impact Learning: Building and Diffusing Learning Capability," Organizational Dynamics 22(2), 52-66.

Wales, J. W., K. V. Gupta, and F. Mousa (2013). "Empirical Research on Entrepreneurial Orientation: An Assessment and Suggestions for Future Research," International Small Business Journal 31(4), 357-383.

Wang, C. L. (2008). "Entrepreneurial Orientation, Learning Orientation, and Firm Performance," Entrepreneurship Theory and Practice 32(4), 635-656.

Wang, C. L., and L. Altinay (2012). "Social Embeddedness, Entrepreneurial Orientation and Firm Growth in Ethnic Minority Small Businesses in the UK," International Small Business Journal 30(1), 3-23.
Weerawardena, J. (2003). "Exploring the Role of Market Learning Capability in Competitive Strategy," European Journal of Marketing 37, 407-429.

Weerawardena, J., and A. O'Cass (2004). "Exploring the Characteristics of the MarketDriven Firms and Antecedents to Sustained Competitive Advantage," Industrial Marketing Management 33(5), 419-428.

Wiklund, J. (1999). "The Sustainability of the Entrepreneurial Orientation-Performance Relationship," Entrepreneurship Theory and Practice 24(1), 37-48.

Wiklund, J., and D. Shepherd (2005). "Entrepreneurial Orientation and Small Business Performance: A Configurational Approach," Journal of Business Venturing 20, 71-91.

Yeo, R. (2003). "The Tangibles and Intangibles of Organizational Performance," Team Performance Management: An International Journal 9(7/8), 199-204.

Zahra, S. A., D. F. Kuratko, and D. F. Jennings (1999). "Entrepreneurship and the Acquisition of Dynamic Organizational Capabilities," Entrepreneurship Theory and Practice 23(3), 5-10.

Zahra, S. A., A. P. Nielsen, and W. C. Bogner (1999). "Corporate Entrepreneurship, Knowledge and Competence Development," Entrepreneurship Theory and Practice 23(3), 169-189.

Zhao, Y., Y. Li, H. S. Lee, and B. L. Chen (2011). "Entrepreneurial Orientation, Organizational Learning and Performance: Evidence from China," Entrepreneurship Theory and Practice 35(2), 293-317.

Zhao, X., J. G. Lynch, and Q. Chen (2010). "Reconsidering Baron and Kenny: Myths and Truths about Mediation Analysis," Journal of Consumer Research 37, 197-206. 